\title{
Witwatersrand Gold Deposits
}

\section{THEIR GENESIS IN THE LIGHT OF MORPHOLOGICAL STUDIES}

\section{K. Hallbauer}

Mining Technology Laboratory, Chamber of Mines of South Africa

Studies of the morphology and other properties of the gold particles in the fossil placer gold deposits of the Witwatersrand provide fascinating glimpses of the conditions under which they were formed. In particular they indicate that in some areas primitive plant life on the deltas on which the gold was deposited acted not only like the legendary golden fleece in concentrating fine gold particles, but probably also reacted biochemically with these particles to determine the forms in which gold is observed in the carbonaceous remains of this plant life today.

In geology ancient events may be studied through their effects on the natural substances of the Earth (1). From the disposition of these substances and from their composition and morphology we can make certain deductions as to the nature of the events that produced them. This applies not only to large bodies of rock but also to the mineral grains of which they are composed.

In the 2500-2 800 million year old fossil placers (2) of the Witwatersrand there lies evidence - in the morphology of the individual gold particles which they contain - of the nature of the processes which led to their formation. Thus recent studies (3) have shown that most of the gold particles in the reefs retain their detrital morphology, and from extensive studies of this morphology important information on the genesis of the deposits has been derived.

The major processes influencing the distribution of gold in the conglomerates have been established as

(1) Alluvial transport from a primary source into an inland basin surrounded by mountains

(2) Concentration by wind and water action

(3) Partial redistribution by biochemical processes within a primitive biological environment and

(4) Partial remobilisation and redeposition by geological processes during metamorphism

All these processes have affected the morphology of the gold particles in Witwatersrand rocks, and three types of gold can be differentiated in the reef, namely, detrital gold, 'biochemically' deposited gold and recrystallized gold.

\section{Detrital Gold}

Gold occurs in its primary deposits mostly as crystalline particles of a more or less complex, jagged morphology, sometimes intergrown with other ore minerals. During the weathering process and subsequent alluvial transport the malleable gold is increasingly deformed by collisions with the accompanying debris. One of the extreme examples where gold is recognised as having been transported for more than $150 \mathrm{~km}$ is the famous 'Rhine gold', found in the upper parts of the river Rhine in Germany. Particles recovered from gravel near the town of Karlsruhe are examples of this flaky, heavily deformed gold (Figure 1). No trace of the original crystalline morphology is left, and

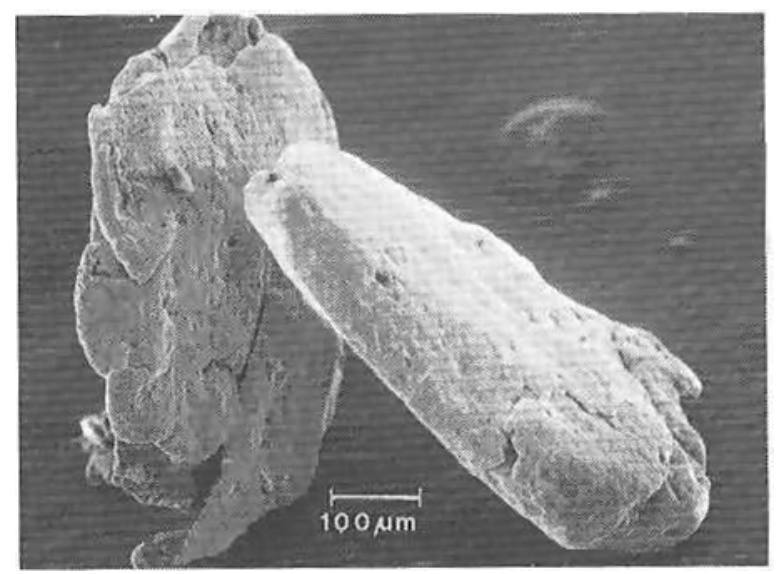

Fig. 1 Flaky gold particles from the Rhine River, Germany. The structures of these particles are typical of those developed during extended fluvial transport 
Fig.2 Jagged, partially flattened gold particles recovered from a specimen of B-Reef, Loraine Gold Mine, Orange Free State

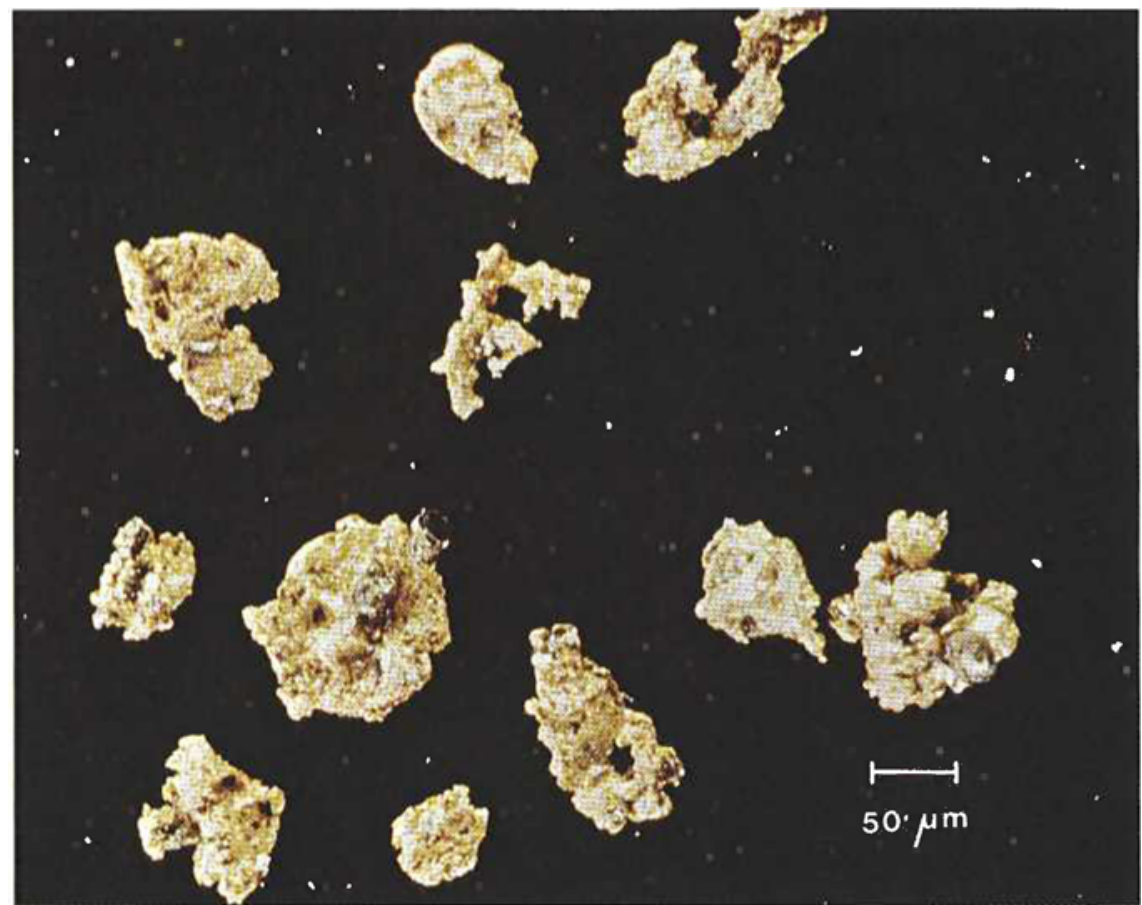

the particles appear to have been flattened and bent several times during river transport. Characteristically, several lace-like wafers of gold may be pressed together to form such particles.

Considering the long geological history of the Witwatersrand rocks it is surprising to find the same and similar micro-textures on the ancient gold particles (Figure 2) after they have been gently liberated from the rock by disintegrating the siliceous matrix in hydrofluoric acid (4). Even rare structures such as those formed by gold being folded around mineral inclusions can be observed (Figure 3).
However, most of the gold particles in the Witwatersrand deposits display micro-textures which indicate short transport distances of a range from 5 to $30 \mathrm{~km}$ (3). Depending on the original shape and size of a particle the initial distortion manifests itself in bending and hammering of the protruding parts, accompanied by scratching and gouging of the surface in all directions. The distortions and abrasions are more pronounced on larger grains and the original crystalline texture is deformed with increasing distance of transport, to such an extent that it may be completely obliterated. The example shown
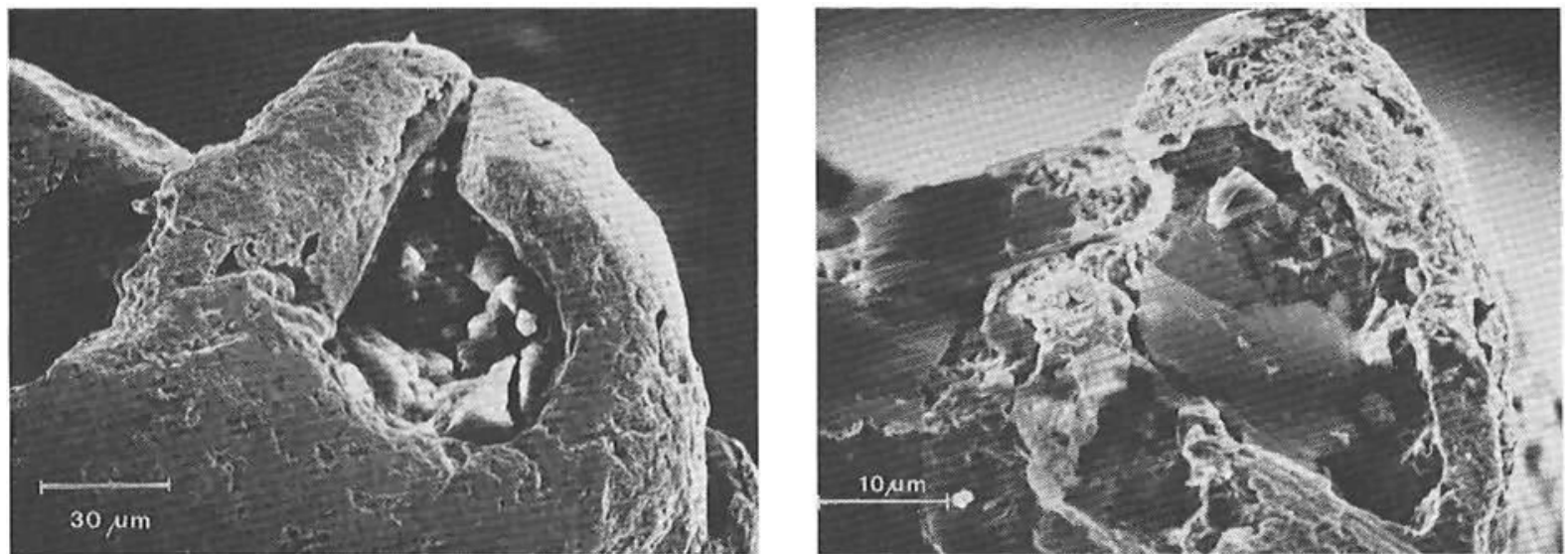

Fig. 3 Partial views in a scanning electron microscope of gold particles deformed around mineral inclusions. On the left is a particle from a Transvaal river, and on the right is a particle from a sample of Basal Reef, St. Helena Gold Mine, Orange Free State 


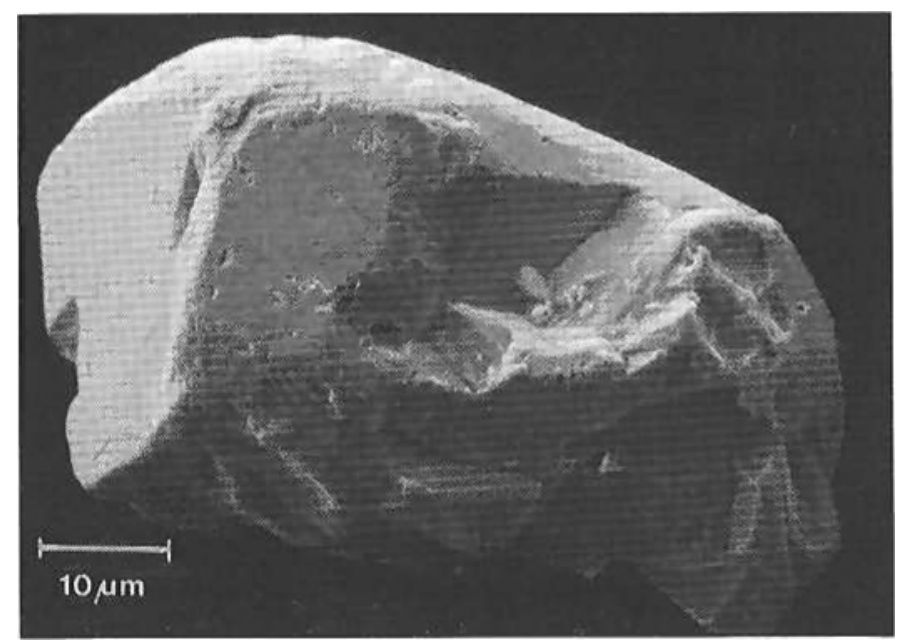

Fig. 4 SEM photograph of an angular gold particle from the B-Reef, Loraine Gold Mine, Orange Free State, showing the initial stages of abrasion and deformation during fluvial transport

in Figure 4 is that of an angular gold grain with remnant crystalline texture but abrasion manifesting itself along the edges and protruding parts. By comparison with recent alluvial gold grains the distance of transport for this and other grains from the same locality is estimated at about $10 \mathrm{~km}$.

Gold grains under the conditions of recent alluvial transport are subjected not only to mechanical distortion but also to chemical attack by sulphate-containing river water which normally has a $\mathrm{pH}$ value of 6-8 and an oxidation-reduction potential of about $+300 \mathrm{mV}$. Under these conditions silver is leached out of the gold, thus increasing its fineness $\mathrm{F}=1000 \mathrm{Au} /(\mathrm{Au}+\mathrm{Ag})$ with increasing distance of transport. No such leaching of silver from gold particles of the Witwatersrand deposits has been observed, and geochemical considerations point to their having been transported in a chemical environment with oxidationreduction potential below $-100 \mathrm{mV}$ and $\mathrm{pH}$ 6-8. The fineness measured for gold particles in Witwatersrand deposits can therefore be taken as the original fineness. This is of potential interest in the geochemical identification of reefs according to the fineness of their gold particles. This often changes both vertically and laterally from one reef horizon to the other and indicates that the often voiced opinion that younger reefs generally represent the reworkings of older eroded reefs (5) may only be true for isolated localities. Derivations from geo-

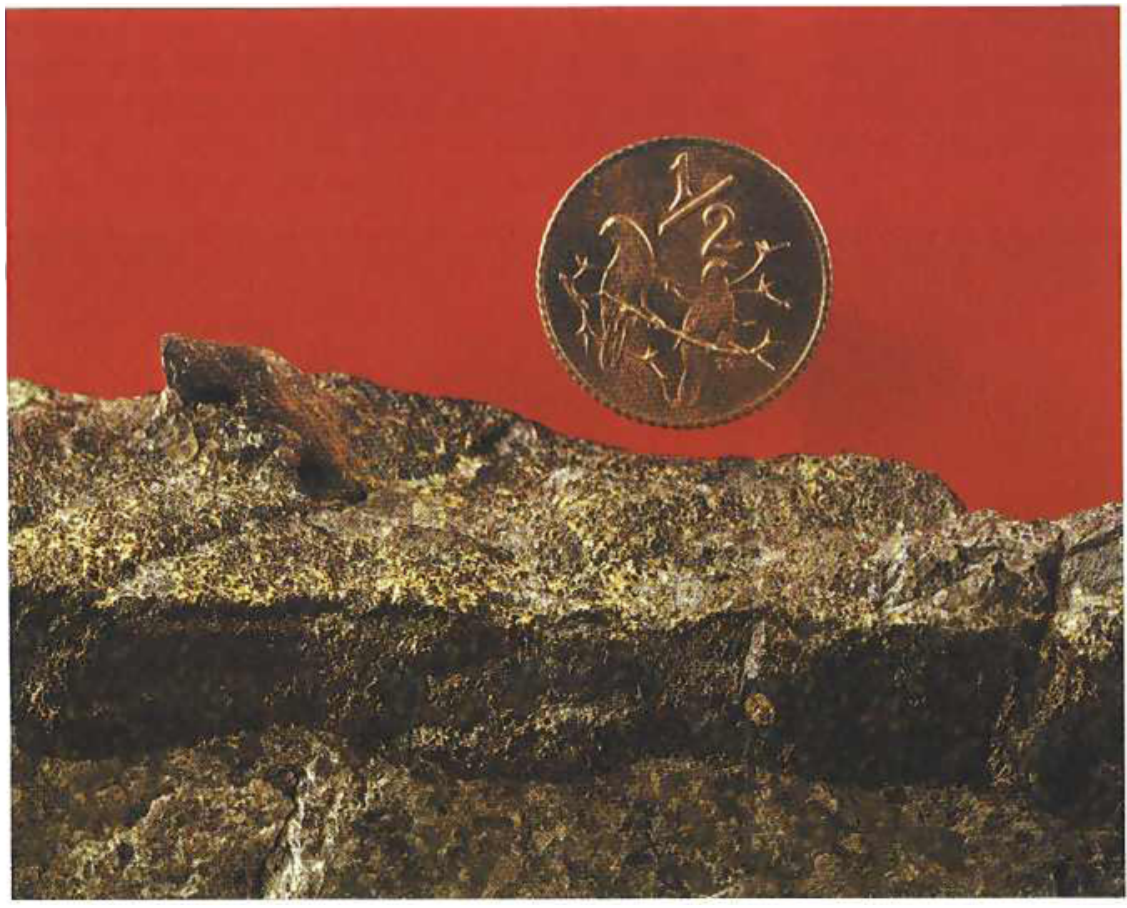

Fig. 5 A specimen of Basal Reef from the St. Helena Gold Mine, Orange Free State, showing a carbon layer with trapped, finegrained detrital gold 
logically related but geochemically different primary deposits, or from geochemically different horizons in the one primary deposit, could be responsible for the variations in fineness which are observed.

More information on the nature of the primary deposits has been obtained from typical detrital gold grains intergrown with other minerals. So far intergrowths between gold and sphalerite, cobaltite-gersdorffite, chalcopyrite, bravoite, pyrite, pyrophyllite and indirectly with molybdenite have been observed. These mineral associations are somewhat different from those commonly found in the Precambrian rocks of the Barberton Mountain land of the Eastern Transvaal, which are commonly taken as a provenance model for the Witwatersrand and point to a type of primary deposit similar to porphyry-type deposits.

It is of interest in this connection that even some of the older sedimentary rocks of the Swaziland sequence in the Barberton Mountain land, the Moodies series, contain small amounts of detrital gold recognizable by the morphology of the particles. This points to the existence of sedimentary, although subeconomic, gold deposits of an age greater than 3300 million years.

\section{'Biochemically' Deposited Gold}

Layers of carbonaceous matter which often accompany the gold bearing strata on the Witwatersrand have been recognised as fossilized Precambrian plant mats (5). In these mats, which occupied the lower parts of the alluvial fans, gold particles were clearly trapped in the same way as they may be trapped by corduroy tables in metallurgical practice, as is evidenced by the many detrital particles which can normally be recovered from layers of carbonaceous matter. Especially fine particles of gold were held back in these mats and consequently layers closely packed with finegrained gold can occasionally be observed (Figure 5).

Apart from such fine-grained gold, and completely locked up within the carbonaceous matter, however, filamentous gold and aggregates of gold filaments occur which point to an intra- and extracellular concentration of gold by the primitive organisms constituting the mats. Although there are no examples from more recent times of the active participation of such plants in the redistribution of gold, there are indications that the gold particles were penetrated and partially or wholly dissolved by biochemical processes. X-ray radiographs of the carbonaceous matter show the relationship between detrital gold and other detrital minerals on the one hand and the biochemically concentrated gold on the other. While detrital gold and other heavy minerals are concentrated in the upper portions and on top of the carbonaceous layer, gold filaments are distributed throughout the fossil plants.

It may be mentioned in this connection that all carbonaceous matter in Witwatersrand deposits contains up to 10 per cent $\mathrm{U}_{3} \mathrm{O}_{8}$. Although this is mostly in the form of uraninite inclusions, fine filaments of $\mathrm{U}_{3} \mathrm{O}_{8}$, which sometimes show well preserved cell structures, can also be observed. Such observations indicate that the primitive plants probably brought about a re-distribution of uranium by biochemical processes, similar to that which is observed in the case of gold.

The biochemically deposited gold does not exhibit any of the features of the detrital gold. It occurs as irregularly shaped, often fibrous particles which often have the appearance of agglutinated, interwoven filaments or perforated flaky par-
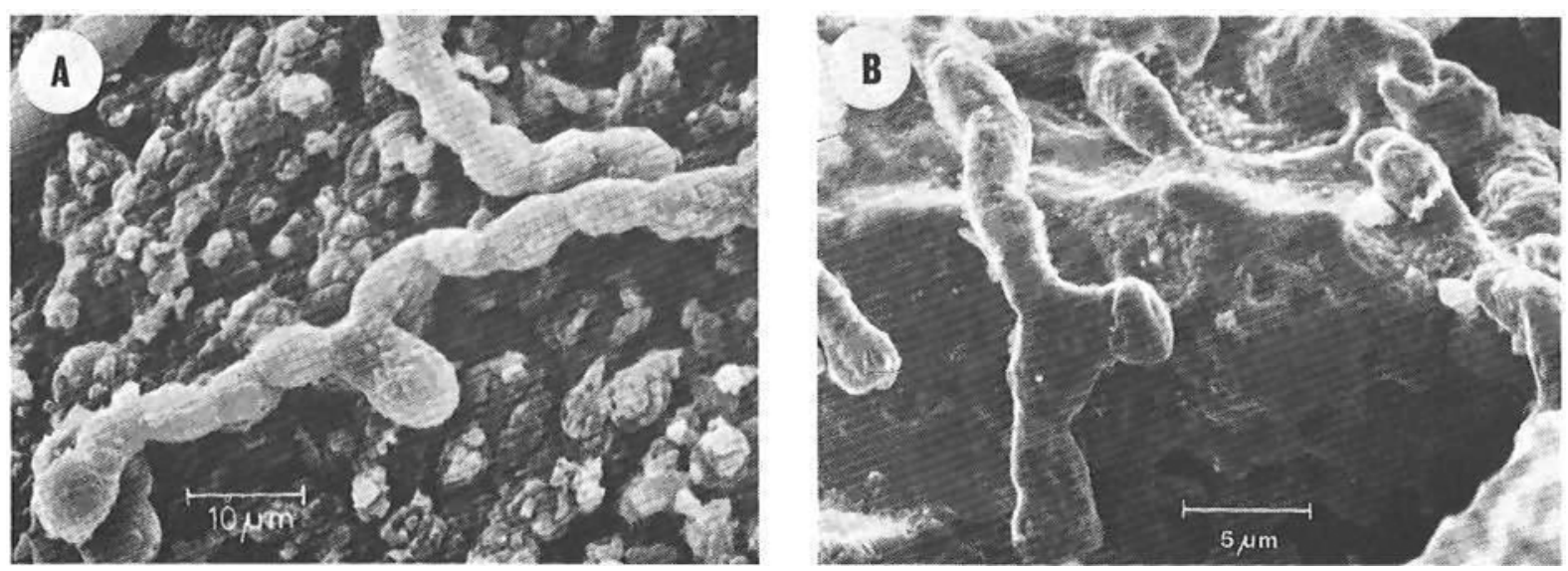

Fig. 6 SEM photographs of a soil fungus (A) with inorganic encrustation ( $\mathrm{Si}, \mathrm{Al}, \mathrm{Fe}$ ) and a gold filament (B) extracted from carbonaceous matter from a Witwatersrand deposit. The gold filament is a fossil gold incrustation on a hypha 


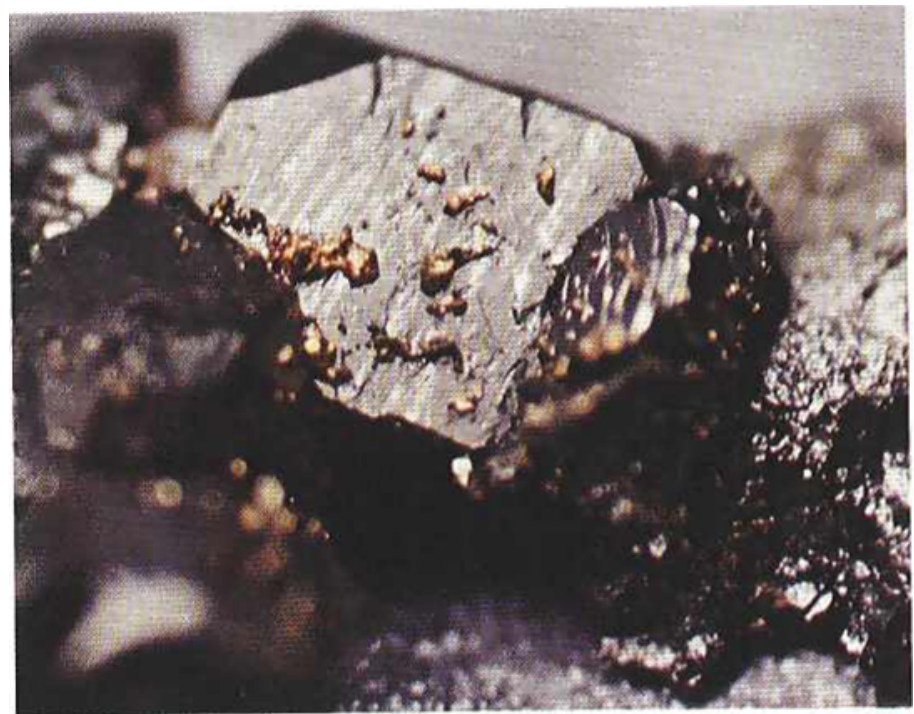

Fig. 7 Secondary growth of gold on a pyrite crystal from a sample of Ventersdorp Contact Reef, Western Deep Levels Gold Mine

ticles. Most filaments have an average diameter of 1-2 $\mu \mathrm{m}$. They are often branched and occasionally show septation similar to algal or fungal filaments.

A comparison of these filaments with inorganic encrustations on some present-day soil fungi (Figure 6) reveals a remarkable similarity. Many modern algae and fungi, the latter especially in lichenized form, have the ability to absorb inorganic materials, including heavy metals (7) from the environments in which they live, and to form extracellular deposits derived from them. A similar process of digesting and redistributing gold and uranium could therefore be assumed for the ancient forms in the Witwatersrand rocks. An additional indication of a biochemical redistribution of the gold is the difference in the silver contents of detrital and 'biochemical' gold. Silver is often enriched in the latter, particularly in samples of Basal reef from the Orange Free State, to concentrations which may be twice those in the associated detrital gold. On the other hand mercury, which is a principal trace element in detrital gold, appears to have been rejected by the organism leaving the biochemical gold with only small traces of this element.

From such geological observations it is evident that the most abundant plant during Witwatersrand times, named Thuchomyces lichenoides (8), thrived in habitats such as those provided by the lower portions of wet alluvial fans, and shallow pools, and that during dry times it survived desert conditions.

Evidence for the existence and active participation of living organisms in the redistribution of heavy metals during Precambrian times is not confined to the Witwatersrand.

The Blind River Conglomerates of the Elliot
Lake district in Canada, for example, contain carbonaceous matter enriched in uranium and thorium which show morphological features similar to the fossil plants of the Witwatersrand, together with structures that can be intepreted as fossilized bacteria.

\section{Recrystallized Gold}

While the detrital gold and the biochemically deposited gold are contemporary with the rocks in which they occur, the recrystallized gold is the product of later, i.e. younger, processes. Although it occurs in comparatively small amounts, its presence is nevertheless a reflection of other processes which have contributed to the generation of the Witwatersrand deposits.

The mild metamorphism to which the rocks have been subjected has evidently not been strong enough to mobilize and distribute the bulk of the detrital gold. Locally, however, near volcanic dykes and fault zones and immediately below thick covers of Ventersdorp lava the temperatures of the rock have clearly been sufficiently raised to mobilize and transport gold for short distances.

The resulting secondary gold occurs almost invariably as an overgrowth on secondary pyrites (Figure 7). The pyrite which has crystal lattice dimensions similar to those of gold has acted as a base for epitaxial growth of the gold. Although gold overgrowths on pyrite are rarely well crystallized, sufficient particles have been observed to indicate that the cube faces of the gold crystals grow on the cube faces of the pyrite rotated by $45^{\circ}$,

\section{Genesis of the Witwatersrand Gold Deposits}

Although at one time the subject of controversy, the fossil placer nature of the Witwatersrand gold 
Fig. 8 Artist's impression of part of the paleo-Witwatersrand with the surrounding mountains in the background and a wet alluvial fan in the foreground. The atmospheres of Precambrian times were low in oxygen and transmitted blue light preferentially. Hence the dominant blue colour of this painting by Dr. F. Kaempfe, Johannesburg

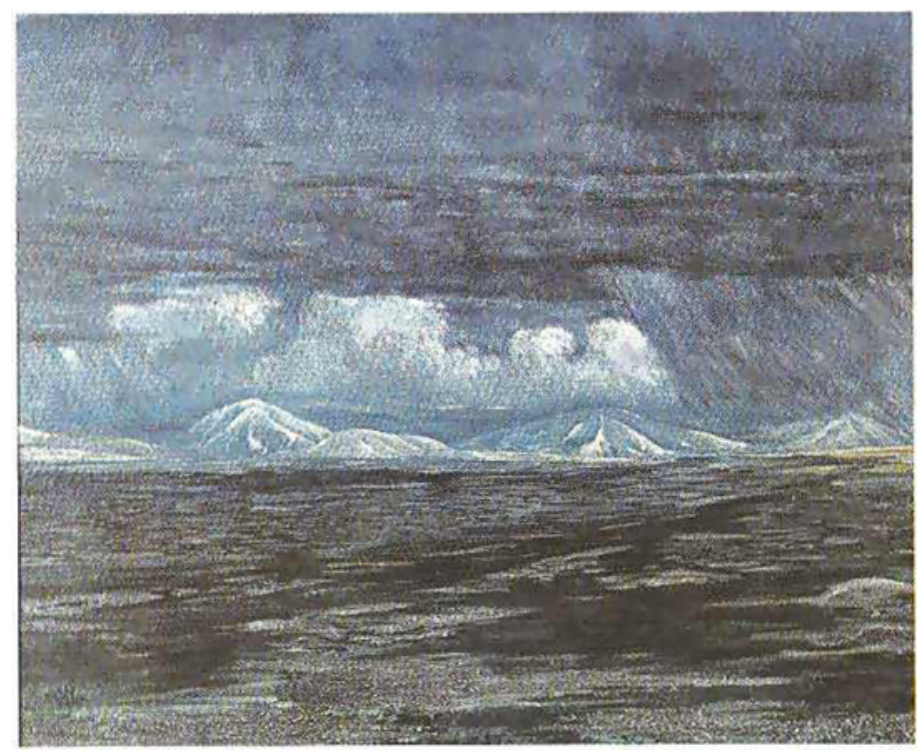

deposits is accepted without reservation by geologists actively involved in study of them. The morphological and other studies of the gold grains which they contain provide convincing support for this view.

The gold bearing conglomerates, or reefs as they are commonly called, represent the final stage of a dynamic series of processes which, although somewhat more complicated, is nevertheless similar to others which we observe daily. If, for example, we notice a smashed flower pot on the pavement in front of a multi-storey building the reconstruction of the dynamic processes which led to the formation of the pot fragments comes quite easily to us. To determine the original direction of flow in a dry or fossilized river bed requires more detailed observations and deductions. Many years of observation by numerous geologists have been necessary in order to enable us to reconstruct to some extent the processes which led to the formation of the largest known gold deposit on earth. The observations on the gold morphology and its significance are but one step in this reconstruction process.

The distribution of gold and uranium in the Witwatersrand deposits is essentially controlled by the paleo-environment. Like any other ecological system the paleo-Witwatersrand consisted of smaller systems in which local environments determined the distribution of economic minerals.

With our present knowledge we perceive the paleo-Witwatersrand as a basin surrounded by mountains of moderate height which were geologically separated from the low-lying area by active faults. Debris washed into the basin formed alluvial fans at the base of the mountains. These fans extended with rapidly decreasing slope angles for several kilometres into the basin. Sheet floods and a system of braided streams reduced the slope angle with time to the average value of about $0.5^{\circ}$ which is characteristic of the Carbon Leader Reef, the Vaal Reef, Basal Reef and others. As indicated by the occurrence of wind-blasted pebbles, the so-called dreikanters, in various parts of the reefs, much of the surface of the fans was subjected at times to desert conditions.

Wind action and water action slowly removed the fine-grained and lighter components of the original gravel deposit until the conglomerate layer, with its accumulation of heavy minerals which is being mined today, remained.

At the lower portions of the alluvial fan biological activity in shallow water and stagnant pools produced thin mats of primitive plants which concentrated gold and heavy minerals both mechanically and biochemically.

Figure 8 is an attempt by Dr. F. Kaempfe, to depict the paleo-environment of a small region of the Witwatersrand. Although it is an artist's creation many a geologist has contributed to it by his painstaking and detailed observations.

\section{References}

1 D. L. Eicher, 'Geological Time', Foundation of Earth Science Series, Prentice Hall Inc., Engelwood Cliffs, New Jersey, 1968

2 D. A. Pretorius, Minerals Sci. Engng., 1975, 7, (1), 18-47

3 D. K. Hallbauer and T. Utter, Miner. Deposita, 1977, (in press)

4 G. J. Neuerburg, four. Research U.S. Geol. Survey, 1975, 3, (3), $377-378$

$5 \mathrm{H}$. C. M. Whiteside et al., in 'Mineral Resources of the Republic of South Africa', Geological Survey, Pretoria, 1976,42

6 D. K. Hallbauer, Minerals Sci. Engng., 1975, 7, (2), 111-131

7 W. Ernst, 'Schwermetallvegetation der 'Erde', Gustav Fischer Verl., Stuttgart, 1974

8 D. K. Hallbauer et al., Geol. Rundsch., 1977 